\title{
ESTABILIZACIÓN DE LAS EXPECTATIVAS EN EL SISTEMA DEL DERECHO Y DE LA POLÍTICA EN MÉXICO
}

\author{
ESTABILIZAÇÃO DE EXPECTATIVAS NO SISTEMA DE DIREITO \\ E POLÍTICA NO MÉXICO \\ STABILIZATION OF EXPECTATIONS IN THE SYSTEM OF LAW \\ AND POLITICS IN MEXICO
}

\section{Raúl Zamorano Farías}

PhD. Filosofia Giuridica, Centro di Studi Sul Rischio UNILE/Italia, Profesor-investigador del Centro de Estudios Teóricos y Multidisciplinarios en Ciencias Sociales (CETMECS), UNAM. Correo electrónico: rzamorano61@ gmail.com.

Convidado

RESUMEN: Sobre la base de la arquitectura conceptual de la Teoría General de los Sistemas Sociales, este trabajo tiene como objetivo observar la forma en la cual en México se han estructurado y operan el sistema del derecho y el sistema de la política, así como de las condiciones de posibilidad disponibles sobre las que se despliegan y estructuran las prácticas y se estabilizan las expectativas de las personas. Es decir, problematizar el problema de la construcción del orden social en la periferia de la sociedad moderna, e indicar las formas en que se estructura un orden generado y estabilizado, precisamente, sobre la base de las experiencias y de las expectativas que allí se producen.

Palabras clave: derecho, política, expectativas, estabilización, orden social.

RESUMO: Com base na arquitetura conceitual da Teoria Geral dos Sistemas Sociais, este trabalho tem como objetivo observar como o sistema jurídico e o sistema político foram estruturados e operam no México, bem como as condições possibilidade disponível em que práticas são implantadas e estruturadas e as expectativas das pessoas são estabilizadas. Ou seja, problematizar o problema da construção da ordem social na periferia da sociedade moderna e indicar os modos pelos quais uma ordem gerada e estabilizada é estruturada, precisamente, com base nas experiências e expectativas que aí ocorrem.

Palavras-chave: Direito; Política; Expectativas; Estabilização; Ordem Social.

\begin{abstract}
Based on the conceptual architecture of the General Theory of Social Systems, this work aims to observe the way in which the system of law and the system of politics have been structured and operate in Mexico, as well as the conditions of possibility available on which practices are deployed and structured and people's expectations are stabilized. That is, to problematize the problem of the construction of the social order in the periphery of modern society, and to indicate the ways in which an order generated and stabilized is structured, precisely, on the basis of the experiences and expectations that are produced there.
\end{abstract}


Keywords: Law; Politics; Expectations; Stabilization; Social order.

SUMÁRIO: Introducción; El derecho y la política como sistemas; Experiencia y expectativas; El sistema del derecho y de la política en México; Conclusiones; Bibliografía.

\section{INTRODUCCIÓN}

Desde la observación sociológica, pensar en evolución implica, necesariamente, pensar tanto en la diferenciación funcional de la sociedad cuanto, en su clausura operativa, así como en la autoconstrucción de complejidad. ${ }^{1}$ Un sistema que evoluciona es aquel que ha reafirmado sus límites respecto a su entorno y, sobre la base de esta diferenciación sus elementos se reproducen autopoiéticamente, lo cual significa -en el contexto de la modernidad de la sociedad modernaque genera su propia complejidad estructural (LUHMANN, 2007: 100; 2010; 1982). ${ }^{2}$

Evolutivamente, los sistemas sociales estabilizan sentidos - expectativas- que sirven para mediar entre la extrema complejidad del mundo y la muy limitada capacidad del hombre para la elaboración consciente de experiencia. ${ }^{3}$ Esta producción y reproducción de sentido está garantizada por la comunicación, que aún cuando eventual, sirve como medio desacoplado para la fijación del sentido de la comunicación (LUHMANN, 1996; 2007: II parte). ${ }^{4}$

Dependiendo de la forma en cómo eventualmente una operación social se actualiza en la realidad, pueden variar los estímulos para la construcción de sentido (de alter y ego) y también la semántica con la cual se registran, organizan y son accesibles determinadas experiencias y expectativas sociales de sentido (LUHMANN, 2007: 261 ss.).

Para la Teoría General de los Sistemas Sociales (TGSS), las fórmulas de sentido comunicativo, denotadas con el término semántica, indican la condensación de una confirmación de sentido generada por medio de su recursividad y su estabilización en la forma de expectativas dotadas de cierta generalidad.

Estabilizar expectativas presupone entonces institucionalizar un cierto ámbito objetivo $e$ indiferente de sentido, donde lo que queda institucionalizado es un horizonte de sentido mas no el factum. ${ }^{5}$ Por un lado, se institucionalizan formas cognitivas sin contenidos y, por otro, algunas expectativas adquieren forma como derechos o garantías individuales (norma), lo cual posibilita crear una franja de indiferencia producto de la irreductible tolerancia modelada por la necesidad de la convivencia humana.

Precisamente, el problema funcional característico de la sociedad moderna es contribuir a la estabilización de la diferenciación social (LUHMANN, 1985; 2010b; 2010c; 2010d; CORSI, 2011), y en ese proceso de estructuración social la institucionalización de las expectativas jurídicas y políticas tiene una función esencial.

\footnotetext{
(*)Este trabajo es producto del proyecto de investigación Observaciones de la periferia de la sociedad moderna.

${ }^{1}$ Complejidad implica que el operar de un sistema debe ocurrir de manera selectiva. Ante una multiplicidad de posibilidades de enlace operativo (complejidad no estructurada), se seleccionan marcos que limitan el rango de opciones actualizables. En la medida en que esa selectividad se mantenga estable, puede hablarse de complejidad organizada (LUHMANN, 1998: 259).

${ }^{2}$ Desde Parsons se reconoce que la diferenciación de los sistemas genera un sistema social más evolucionado en la medida en que presenta mayor capacidad de adaptarse (PARSONS, 1987: 39-41).

${ }^{3}$ Luhmann (2002) no entiende un sistema como un entramado congruente de reglas, sino como un entramado de operaciones fácticas que, como operaciones sociales, deben ser comunicaciones, independientemente de lo que estas comunicaciones afirmen.

${ }^{4}$ Entonces, a diferencia del sentido subjetivo de la acción del sujeto, la operación y vivencia social son entendidas por la teoría general de los sistemas sociales como constelaciones de atribución de sentido, que sirven para observar las operaciones comunicativas.

${ }^{5}$ Institucionalización como la estructuración de las expectativas. Es decir, la civilización de las expectativas que devienen institución (ZAMORANO FARÍAS, 2017).
} 
Al observar la evolución del sistema del derecho y del sistema de la política, tal y como fue cimentado entre los siglos XVIII y XIX, se constata que esta semántica respondió a las condiciones socioculturales y a los arreglos constitucionales de la época, principalmente desde la desilusión del supuesto orden natural con todas sus asimetrías y dogmatismos, hacia la radical diferenciación social. Adquisición evolutiva que, en el arco de poco más de un siglo, se han transformado profundamente y en donde la política y el derecho no pueden ya depender del fundamento 'natural', de la moral o de las costumbres legitimadas por los nobles. ${ }^{6}$

\section{El derecho y la política como sistemas}

Es sabido que la historia institucional del derecho y de la política es la historia del conflicto y de la superación de la arbitrariedad/discrecionalidad en el conflicto. En las sociedades orientadas por un orden social premoderno (estratificado), los diferentes sistemas interpersonales de acción se caracterizaban por la arbitraria indiferenciación, de forma que la vida comunitaria era regulada por el carácter del comportamiento discrecional, toda vez que el contenido del derecho y de la moral estaban definidos y legitimados por la divinidad o la natura.

Evolutivamente, y en virtud del proceso de diferenciación social, la moral y el derecho se van distinguiendo y, con la positivación del derecho, se estabiliza la diferenciación operativa entre comunicación legal y comunicación moral. La estabilización del sistema del derecho deviene así un presupuesto de la sociedad moderna, proceso que genera esencialmente la expansión de posibilidades de acción, tal que el enlace punto por punto con un pasado de hábitos y costumbres ya no es posible de controlar, eliminando la dependencia del uno sobre el otro e instituyendo, finalmente, el derecho y la política como sistemas autónomos. ${ }^{7}$

Para Luhmann (2002; 2004, 2004b; 2005; 2010), la diferenciación del derecho se hace posible cuando éste adquiere la forma de un programa condicional y, por lo tanto, supone un nivel eficaz de indiferencia con respecto a la diversidad (entorno). ${ }^{8}$ El derecho deviene así en la totalidad de las normas coercitivas, mientras que las normas no coercitivas -morales- quedan en el ámbito de la conciencia (derecho no oficial: TEUBNER, 2005). En consecuencia, la coordinación operativa de la acción requiere la disponibilidad de estructuras simbólicamente generalizas que orientan pero que no determinan la acción, pues éstas ya no pueden ser proporcionadas por la divinidad o por moral como valor de referencia (lo bueno y lo malo). ${ }^{9}$ Lo anterior significa, entre otras cosas, que se requiere de la disponibilidad de condiciones, de estructuras reguladoras para estabilizar la institucionalización del imaginario normativo (derecho) así como también de su

\footnotetext{
${ }^{6}$ Sabido es que la fuente del contractualismo y del Estado moderno está estrechamente vinculada con las guerras religiosas y monárquicas de la Europa medieval y la consecuente civilización de las expectativas frente al miedo generado por la muerte violenta. Ciertamente, allí no cabe decidir cuánto tiempo será necesario para llegar a esta superación, ni cuánto tiempo se estará luchando por conseguirla.

${ }^{7}$ Las condiciones que han favorecido la diferenciación funcional presuponen el establecimiento de una forma de poder central y el paso de formas espontaneas de reacción de la conducta, hacia formas de control regulado (coacción y autocoacción características del proceso civilizatorio) (ELIAS, 1994). Universalización y clausura operativa son a la vez precondición semántica y comunicativa para que se puedan diferenciar sistemas funcionales operativamente clausurados (LUHMANN, 1991; 2007).

${ }^{8}$ Construir programas condicionales es indicar el cómo. Los programas condicionalles son concebidos como modelo de operación, lo cual constituye una de las premisas organizacionales más importantes del orden social diferenciado, aún cuando puedan ser establecidos con carácter general sin comunicar ninguna predicción precisa de la cantidad de detalles en las situaciones en las cuales se aplicará. Precisamente, los programas funcionan como mecanismos para evaluar la adecuación situacional de las decisiones, en donde la regulación alcanzada indica aquello que debe y no debe de hacerse ante determinadas situaciones, especificando las condiciones que deben satisfacerse para que se desencadene un determinado procedimiento. En este sentido se delinean por la forma solo si-entonces (LUHMANN, 2010: 307).

${ }^{9}$ La moral es aquello a la que me siento obligado, la ley es aquello a lo cual me obliga el poder del Estado.
}

Revista de Direito Brasileira | Florianópolis, SC | v. 24 | n. 9 | p.101-119 | Set./Dez. 2019 
variabilidad. Variabilidad que al liberarse del valor moral hace posible el aprendizaje continuo, incluso en presencia de las posibilidades de resistencia. ${ }^{10}$

Lo anterior admite que en un orden social con preeminencia en la diferenciación funcional-operativa (modernidad), todos los temas pueden ser regulados normativamente (con leyes que se desprenden de las leyes), lo cual se manifiesta como producto de una decisión y por lo mismo puede ser apoyado por el uso de la fuerza física (WEBER, 1980). Precisamente, el elemento clave de la diferencia entre las estructuras pre-jurídicas y jurídicas es la institucionalización del derecho para imponer la aceptación generalizada y despersonalizada de su contenido. El derecho moderno es resultado entonces de la progresiva secularización de la estructura normativa regulada por la sociedad, es decir, de la distinción entre lo divino y lo terreno.

Evolutivamente, la separación entre moral y derecho constituyen, obligatoriamente, lógicas de comportamiento específicos. Por un lado, se genera una externalización en la institucionalización, lo que pone de manifiesto al derecho como un sistema operativo específico de orden despersonalizado. Por otro lado, paralelamente tiene lugar la internalización de ese orden social, dejando en claro que la moral está referida a las obligaciones internas de la persona, mientras que el derecho a sus operaciones externas, pues se acepta que el derecho no es un fenómeno moral, sino un fenómeno político, una exteriorización del poder social: una institución del imaginario radical (CASTORIADIS, 2013; 2001; 1990).

La diferenciación entre derecho y moral presupone, además, la generación de estructuras normativas y de procedimiento que sirven a la legalización de otras reglas y que hacen que el problema de su validez sea independiente de juicios de valor, ${ }^{11}$ porque a través de las regulaciones y programas condicionales generados por y en la ley, el derecho del Estado orienta un cierto orden de comportamientos y hace legítimo el uso de medios de coerción en contra de aquellos que se comportan de una manera contraria a las normas legales. ${ }^{12}$ Así, el derecho no sólo sirve para mantener y garantizar las condiciones mínimas para la existencia y la variación del orden social moderno, sino que también propone la tarea de acoplar efectivamente las acciones de los diferentes sistemas de la sociedad a través de un relativo y bajo grado de conflicto en pos de resolver por medios pacíficos los casos de conflicto, lo cual de manera alguna significa eliminarlos, así como tampoco la imposibilidad del uso legítimo de la violencia del Estado.

Precisamente, la eficacia del derecho moderno descansa fundamentalmente en el hecho de que este sistema produce posibilidades de comunicación social, sobre la base simbólica del posible uso de la fuerza física. En el derecho, por lo tanto, la posibilidad del uso del recurso a la fuerza está ligada no sólo a las estrategias de contención de la disidencia, sino también a las estrategias destinadas a la producción de consenso -cumplimiento de la ley-, porque el presupuesto de la sanción legal es siempre un hecho ('objetivo' sobre la base de la norma), cosa que no acontece con la comunicación moral. ${ }^{13}$

\footnotetext{
${ }^{10}$ (LUHMANN, 2002, 134). Kant (1784) concibe el derecho como ese el conjunto de condiciones por las que el libre arbitrio de cada uno pueda concordarse con el de los demás según una ley general de libertad (sapere aude).

${ }^{11}$ Incluso si se argumenta que el derecho sería un derivado de los valores morales, pues la única forma posible de criticar el derecho sería falsificar entonces el derecho con otra moral.

${ }^{12}$ Es la distinción entre convención/costumbre, cuya validez está garantizada externamente por la probabilidad de que una conducta discordante habrá de tropezar con una (relativa) reprobación general y prácticamente sensible, y derecho, el cual está garantizado externamente por la probabilidad de coacción (física o psíquica) ejercida por un cuadro de individuos instituidos con la misión de obligar a la observancia de ese orden o de castigar su transgresión (WEBER, 1980; 1989), y si bien coacción significa posibilidad del uso de la fuerza física, la aceptación o el rechazo de la comunicación normativa desencadena también recursiones diferentes y explica además cómo surgen instituciones de superación de los conflictos que deben focalizarse sobre casos particulares, de divergencia imprevisibles, de opiniones y/o antagonismos (LUHMANN, 2007, 2010c, 2010d).

${ }^{13}$ Que es del todo arbitraria y personal, aun cuando la alternativa propuesta haya sido que la sociedad moderna tuviese la posibilidad de integrarse sobre la base de una única moral generalizada. Eso que señala Durkheim (2001) cuando sostiene que el deber fundamental del Estado es perseverar en inculcar al individuo una forma moral de vida.
}

Revista de Direito Brasileira | Florianópolis, SC | v. 24 | n. 9 | p.101-119 | Set./Dez. 2019 
Si bien esta generalización reflexiva, sumada a la capacidad de uso de la fuerza, permiten al derecho llegar a un máximo de indiferencia con el entorno, incluso al costo de la individualidad, asegurando la confianza y expectativa en el futuro social, esto no ocurre con referencia a la moral, pues la moral pone a disposición una variabilidad muy pobre y limitada de adaptación y confianza social. La comunicación a través del derecho se lleva a cabo, por lo tanto, con mayor rapidez, puesto que incluye todas las comunicaciones sociales que se desarrollan en la ley a través de la ley.

Consecuentemente, en las sociedades complejas, esta lógica operativa pone también de relieve sus limitaciones. La estabilidad y la inestabilidad, la conservación y el cambio, el conflicto y la integración no se producen más como categorías antitéticas. Al contrario, evidencian claramente que el derecho no soluciona los conflictos, sino que tan solo genera y define un marco para que en su interior se desplieguen, desarrollen y tematicen los conflictos (LUHMAN, 2002). Baste reconocer que la evolución del sistema social llamado sociedad produce un orden contingente altamente improbable. ${ }^{14}$

La combinación entre apertura cognitiva y clausura operativa de los sistemas sociales es una de tales improbabilidades, porque la elemental existencia del derecho -y del Estado de derecho- no asegurará automáticamente su aplicación y observación. Incluso una ley/norma puede permanecer total o parcialmente inaplicada, ya sea que su contenido no es suficientemente claro o porque no se consideran relevantes ni el nivel ni y grado de posibles sanciones. Por lo tanto, el derecho no debe observarse exclusivamente en su función coercitiva, de acuerdo con la concepción clásica del pensamiento jurídico (racionalidad formal), sino más bien como un medio para guiar el comportamiento, para seleccionar y estabilizar variaciones y proporcionar - en la improbabilidadseguridad y confianza a las expectativas de las personas; sobre todo, si las cuestiones a él relacionadas se encuentran necesariamente tipificadas en las leyes, en los principios constitucionales, en los reglamentos y en los precedentes que se tienen (experiencia - expectativa), y no en la voluntad o arbitrio de la persona.

Paralelo al derecho, la diferenciación del sistema de la política, cuya función es la toma de decisiones colectivamente vinculantes, a través de mecanismos que permiten generalizar socialmente las expectativas atribuyendo fuerza vinculante a una decisión, se acopla al sistema del derecho para diversificar el acceso al poder concentrado políticamente (LUHMANN, 2002: 139, 208, 209). Lo anterior no implica que ambos sistemas se confundan, toda vez que el presupuesto funcional es la diferenciación entre el sistema del derecho y el de la política.

$\mathrm{Si}$ como producto evolutivo típicamente moderno, la moral y el derecho se van diferenciando sobre la base de la positivización del derecho, el institucionalizar la oposición a través de la organización (gobierno/oposición), caracteriza la diferenciación del sistema político moderno (ZAGREBELSKY, PORTINARO, LUTHER, 1996; LUHMANN, 2002; 2004).

Recordemos que las sociedades antiguas tenían una forma de dominio político (señores, reyes, nobles), que definían la estructura y el orden social; una lógica de legitimación natural, divina en donde la contingencia era instalada en la rivalidad, en tanto antecedente primario de la oposición (puesto que nadie podía colocarse al mismo nivel ni ocupar el lugar del Rey o del señor y tan solo eran relevantes -y a veces determinantes- los grados de cercanía o lejanía con el 'Sol'). Incluso, cuando la rivalidad se podía justificar jurídicamente, es decir articular el derecho para ocupar el puesto del Rey, el fundamento de ese derecho debía responder por igual al orden divino o natural. El resultado operativo y evidente es que, en la semántica de la época, todo se mezcla: lo jurídico con lo religioso, el Rey con el tirano, la moral con lo familiar, lo religioso y lo político.

Será en el siglo XVI, que esto se va a modificar toda vez que surge el problema de cómo definir conceptualmente la facultad legítima de poder del monarca. Se inventa entonces el vocablo y la facultad de arbitrio (que se encuentra en el vértice), lo cual significa que el poder vale para los

\footnotetext{
${ }^{14}$ Contingentemente, el orden social diferenciado enfrenta situaciones en las que su estabilidad y reproducción no excluyen el cambio o la permanente posibilidad de conflictos. Específicamente, en el sistema del derecho, toda producción de derecho genera un no derecho, toda inclusión una exclusión (LUHMANN, 2007).
}

Revista de Direito Brasileira | Florianópolis, SC | v. 24 | n. 9 | p.101-119 | Set./Dez. 2019 
otros y también para el monarca (HOBBES, 1994). ${ }^{15}$ Tal que la posición del arbitrio no tiene que ver ya solamente con el jus naturis, sino -como explica Machiavelli (1980)-, también con el uso del medio del poder del gobernante, que presume estar a favor de los gobernados (virtù).

La paradoja de este arbitrio, aplicado a la política, significa entonces que la incertidumbre internalizada (no ya la fortuna) se aplica observando al detentor del poder, y también que se constituye en uno de los primeros signos de lo que será llamado posteriormente decisión. Decirium significa justamente que todo lo que se hace tiene una alternativa. Así se pasa del "Estado soy yo" al procedimiento, que garantiza legitimidad independiente del dominio (se pasa de la disponibilidad personal a la estructura).

Evolutivamente, este procedimiento se legitima por sí mismo (derecho y política moderna) articulándose sobre la diferencia/distinción gobierno y oposición. Precisamente, se habla de democracia cuando existe al menos oposición. Oposición política (una distinción típicamente moderna: siglo XVII - XVIII) que probablemente surge cuando el gobernante se debe diferenciar dos veces: diferenciarse de los gobernados y diferenciarse de la oposición (siglo XIX - XX) (CORSI, 2011; LUHMANN, 2002: 138-140).

Tal que un valor esencial es el orden materializado en reglas, en tanto un valor constitutivo de la sociedad moderna, que permite la estabilización de expectativas recíprocas de comportamiento toda vez que estabiliza certidumbre sobre lo que se puede y lo que no se puede hacer asegurando formas de integración social. Esta es la mayor ventaja que se deriva de la complejidad social, una delimitación de su espacio, en el sentido de la autopoiesis creativa de lo político y no de su abstracta e ilimitada autonomía -característica del arbitrio personal o del tirano.

Se trata ahora de un sistema político autopoiético para establecer y legitimar, en un contexto determinado, las formas y prácticas de poder y desplegar libremente todo su potencial e interactuar con todos los otros sistemas autopoiéticos. Es decir, el poder se convierte aquí en potencia compleja, que es el polo opuesto de la categoría poder absoluto, puesto que tanto el poder de la política y del derecho se acoplan con el desafío representado por el problema de la utilización de los recursos, avalando y profundizando los presupuestos de la confianza y de las expectativas sociales.

El reconocimiento de estas dimensiones epistemológicas (no terapéuticas), socava entonces cualquier intento de retorno a los postulados clásicos que reivindican un supuesto carácter prescriptivo y universal de la expectativa política-democrática, más aun cuando en las sociedades complejas el problema del sistema político no es dar respuesta a todas las preguntas desde un supuesto vértice político, sino más bien, seleccionar, reaccionando frente al entorno para reducir la complejidad, para reproducir sus propias reglas y cambiar sus contextos internos, anticipando cuanto sea posible -sobre la base de su experiencia- algún resultado catastrófico, implicado por la complejidad de su entorno. ${ }^{16}$

Será entonces sobre la base de la experiencia y las expectativas, que el sentido y el objeto del dominio político-jurídico estatal viene a garantizar y arbitrar un orden social a través del instrumental normativo para su realización. Es decir, con la creación y promulgación de leyes generales que contribuyan a la estabilización de la diferenciación social, delineando y manteniendo los límites institucionales entre las instituciones legales de los subsistemas, y el logro de una mayor y estructurada complejidad dentro de ellos (LUHMANN, 1985: 5, 6; ZAGREBELSKY, PORTINARO, LUTHER, 1996).

Como se ha señalado, lo anterior presupone que, en la sociedad moderna, cualquier disputa o cualquier comportamiento extra organizacional es seleccionado sobre la base de la contraposición entre lo lícito y lo ilícito, o entre lo constitucional e inconstitucional, contribuyendo a la

\footnotetext{
${ }^{15}$ Recordemos que desde Hobbes (1994) se difunde la idea que no sea más la naturaleza, sino la razón la que guía las elecciones y los comportamientos (administración de la violencia).

${ }^{16}$ Aún más, en este sentido Luhmann señala que el problema del sistema político no es el exceso de poder, sino su déficit (LUHMANN, 2010b).
} 
reproducción de un instrumento capaz de reducir y, por lo tanto, también de aumentar la complejidad alcanzable tanto por el sistema jurídico cuanto por el sistema político.

Co-evolutivamente, y de forma paralela, la diferenciación del sistema de la política se acopla (utiliza) al sistema del derecho para diversificar el acceso al poder concentrado políticamente (LUHMANN, 2002: 208, 209), mas y a diferencia del derecho, la política utiliza el medio del poder, articulando un poder indicativo superior que coacciona con su carácter obligatorio. Lo anterior no implica que ambos sistemas se confundan, toda vez que el presupuesto funcional es la diferenciación funcional y operativa entre el sistema del derecho y el sistema de la política, cuya función es también diferente.

El sistema del derecho y el sistema de la política, en tanto nuevas formas de organización, eliminan una larga tradición de estructuras centralizadas y presuponen sus correspondientes semánticas y códigos de operación (LUHMANN, 2004: 217; 2007; CORSI, 2011). Así, tal y como los otros sistemas diferenciados, el sistema político y el sistema del derecho devienen una conquista civilizatoria irrenunciable, que actúan como factores de inclusión/exclusión, de construcción y de afirmación de las estructuras y expectativas, cuanto como del reconocimiento y expansión de los derechos, del estado de derecho, de la ciudadanía y de la democracia (FERRAJOLI, 2011).

\section{Experiencia y expectativas}

Mientras la política constriñe orientando las decisiones colectivamente vinculantes, el derecho, generado por la necesidad de seguridad, se concentra no tanto a las conductas cuanto a las expectativas que se derivan del problema de la doble contingencia de la vida social. Si el hombre ha de gobernarse por leyes razonables, el sistema del derecho se orienta entonces hacia el mantenimiento estable de tales expectativas razonables, aún cuando estas resulten vanas, porque dichas expectativas son normas que permanecen estables independiente de su eventual violación (LUHMANN, 1996; 2002).

Así, el derecho garantiza precisamente una delimitación de lo que puede esperarse en el tiempo y, en tal sentido, limita la libertad y separa claramente lo aceptable de lo no aceptable (expectativa normativa), haciendo plausible el anclaje con un futuro que es siempre improbable (CORSI, ESPOSITO Y BARALDI, 1996: 54). Por un lado, el derecho juega un rol constitutivo crucial, organizando formalmente y estabilizando los dominios distintivos de la acción, esto significa, creando el marco institucional de subsistemas sociales específicos (TEUBNER, s/f). Por otro lado, juega un rol regulador, coordinando las racionalidades sectoriales de aquellos subsistemas especializados y manteniendo la diferenciación social contra las tendencias expansionistas que puedan emanar de subsistemas particulares (LUHMANN, 1985; TEUBNER, $\mathrm{s} / \mathrm{f})$.

Así, mientras la política tiene la función de mantener la capacidad societal de tomar decisiones colectivamente vinculantes, el derecho tiene por función la estabilización de las expectativas normativas (expectativas de comportamiento). Entonces, la elección de las expectativas de comportamiento (cognitivas) son susceptibles a la generalización y a la inmunización simbólica de otras posibilidades, por lo que pueden reducir los riesgos de su incumplimiento, toda vez que las expectativas normativas generan una retícula suficientemente estable de posibilidades para referirse y orientar un comportamiento que, en su base, paradójicamente tiene fundamentos inciertos (probabilidad de la improbabilidad). Estas referencias se constituyen como las expectativas normativas que, a diferencia de la experiencia cognitiva, mejoran la precisión de lo posible, de lo incierto.

Expectativa normativa como una acumulación y estabilización de las impresiones y de las prácticas anteriores. Una especie de vínculo con el pasado que dispone la expectativa cognitiva (no determina), orientando la espera del proyecto futuro que se ha construido sobre la base de esa experiencia para proyectar certezas relativas al por venir. Tal que la expectativa es un futuro 
presente que se articula en la experiencia del pasado presente, porque toda expectativa se deriva de la experiencia, y como observa Koselleck (1993: 31), el futuro aparece siempre más o menos como lo contenido en lo que se da en el tiempo (en las constelaciones del tiempo fundamental), articulando diferentes tipos de relación para generar y mantener la historia factual (estructura) y su script cultural (semántica), ${ }^{17}$ pues el presente es la unidad de la diferencia pasado/futuro y precisamente por ello también la unidad de la diferencia redundancia/variedad (LUHMANN, 2007: 798).

Esta diferencia entre expectativa y experiencia es especialmente significativa en la sociedad moderna y además es uno de los elementos que la caracterizan, al ser capaz de unificar en un solo principio la diferencia de tiempo entre la experiencia y la expectativa, incluso cuando las expectativas no tengan el mismo grado de previsibilidad, sobre todo si la desnuda contingencia de los hechos nos permite identificar las expectativas menos estables (cognitivas), en las relaciones con otros hombres, que se caracteriza por la doble contingencia (alter - ego), las cuales se basan preeminentemente en la incertidumbre. Tal que la representación de intereses y expectativas está condicionada también por las representaciones y expectativas que tienen los demás.

Por lo tanto, cuando un patrón mayor de comportamiento recursivo es institucionalizado, tipificado de una manera social aprobado por las leyes, normas, reglamentos, costumbres, hábitos, genera una mayor probabilidad de que el comportamiento dará lugar a la misma autotipificación del estado de cosas que se esperan. De ahí que el derecho viene observado como uno de los medios más apropiados para lograr este proceso de institucionalización, ya que puede facilitar expectativas a través de su congruente generalización y así reproducir o generar otras posibilidades funcionalmente equivalentes, eliminando la brecha entre ser y deber ser.

Retrospectivamente, al observar la estabilización del derecho, a través del ordenamiento constitucional, vemos como las fuerzas sociales que estaban suprimidas por el ancien régime, fueron liberadas creando las precondiciones políticas e institucionales para la emergencia de actores políticos totalmente nuevos. Lo anterior asentó los presupuestos y estructuras para que, en la sociedad moderna, cualquier disputa o cualquier comportamiento extra organizacional fuera seleccionado sobre la base de la contraposición entre lo lícito y lo ilícito, o entre lo constitucional e inconstitucional, contribuyendo a la reproducción de un instrumento capaz de reducir y, por lo tanto, de aumentar la complejidad alcanzable tanto por el sistema jurídico cuanto por el sistema político.

Precisamente, el derecho resuelve un problema temporal que se presenta en la comunicación social, cuando la comunicación en proceso no se basta a sí misma (tanto como expresión, cuanto como "práctica") y tiene que orientarse y expresarse en expectativas de sentido que implican tiempo. Ello permite observar que la función del derecho está relacionada con expectativas (orientadas al futuro), esto es, con la posibilidad de comunicación de expectativas de comportamiento y, con esto, con el reconocimiento de tal comunicación (LUHMANN, 2002: 182).

Para decirlo en otras palabras, el derecho tiene la función "de prepararse, al menos en el nivel de las expectativas, ante un futuro incierto - genuinamente incierto. Por eso con las normas varía la medida en que la sociedad produce un futuro acompañado de inseguridad" (LUHMANN,

\footnotetext{
${ }^{17} \mathrm{Al}$ respecto, Koselleck señala la necesidad de investigar paralelamente en torno a la historia social y a la historia conceptual, como aspectos inseparables, aunque distintos y considera cuatro formas típicas en las que se podrían clasificar estas formas de relación. El primer tipo refiere a los casos en los que el sentido de los conceptos y el estado histórico de cosas parecen corresponder tanto de manera sincrónica como de manera diacrónica; lo cual es un fenómeno altamente improbable. El segundo tipo contempla los casos en los que el significado de una palabra permanece igual, mientras que los estados históricos de cosas se modifican significativamente. El tercero incluye casos en los que la evidencia histórica permanece relativamente constante mientras que los significados de los conceptos se modifican. El cuarto grupo abarca casos en los que los actos y la articulación lingüística de los mismos se encuentran completamente separados. Incluso el concepto de sujeto moderno se vincula con este cambio en la concepción del tiempo pues el sujeto se considera el agente que realiza lo nuevo (KOSELLECK, 2012: 32).
}

Revista de Direito Brasileira | Florianópolis, SC | v. 24 | n. 9 | p.101-119 | Set./Dez. 2019 
2002: 187). ${ }^{18}$ Entonces, adquiere notabilidad la cuestión de la repetición en el tiempo, a fin de intentar estabilizar tal inseguridad (probabilidad de lo improbable). ${ }^{19}$ Es, decir, reconocer que las conexiones temporales generan tanto la conformidad cuanto la desviación de conductas, creando una permanente tensión entre la dimensión temporal y la dimensión social en donde, precisamente, la norma y las decisiones queden siempre abiertas a posibilidades de incumplimiento.

Para Luhmann el derecho de un sistema social no es, por lo tanto, un ordenamiento coactivo (ni un deber ser ni una sanción), sino una forma de facilitar y posibilitar expectativas mediante generalizaciones congruentes que disminuyen el riesgo, siempre presente en expectativas que se fijan como resistentes a los hechos, contribuyendo así a la estructuración de la complejidad (LUHMANN, 1985: 5, 6; ZAGREBELSKY, PORTINARO, LUTHER, 1996).

Como se indicó, los sistemas a través de sus organizaciones comunican decisiones y mantienen su operación precisamente porque éstas se vinculan a nuevas decisiones. La decisión es entonces una comunicación de la selección de una alternativa y solo las alternativas hacen de la decisión una decisión (LUHMANN, 2010b: 166), lo cual presupone además que estas operaciones son siempre contingentes, pues la posibilidad de elegir otra alternativa se encuentra también siempre disponible (LUHMANN, 2015).

$\mathrm{Si}$ se toman en serio estos presupuestos de la modernidad de la sociedad moderna (LUHMANN, 1998b: 131), se puede observar que los sistemas sociales y sus organizaciones se enfrentan constantemente a escenarios de incertidumbre que provienen de la forma en la cual se analiza el problema de la complejidad. Pensemos, por ejemplo, en el sistema de la política o del derecho; en donde para que un valor sea elaborado como una decisión que vincula colectivamente y se integre a un programa de la organización, deben estabilizarse mecanismos que definan los canales que la comunicación ha de seguir, esto es, limitar la infinidad de cursos probables que pueden tomar las decisiones y obligar a su cumplimiento, porque si estas expectativas no se concretizan se sospecha inmediatamente de corrupción (CORSI, 1998).

\section{El sistema del derecho y de la política en México}

\section{Si todos los archivos contaban la misma mentira, la mentira pasaba a la historia y se convertía en verdad.} (GEORGE ORWELL, 1984)

Si la característica de la sociedad moderna está dada por la desilusión del supuesto orden natural, la decisiva preeminencia de la diferenciación social y si, además, la democratización del sistema político y la positivización del derecho han evolucionado, merced a la permanente irritación y reciproca estimulación en la construcción del orden social, cómo opera entonces el orden social en México cuando estos presupuestos y adquisiciones evolutivas vienen supeditados a la politización del derecho y la juridificación de la política (formalismo legalista), en un orden social cuya preeminencia operativa esta asentado sobre un conjunto de estructuras estratificado, y en donde incluso se ha pensado (y se piensa) frecuentemente, o peor, se actúa como si los presupuestos de la modernidad no tuviesen que ver con la realidad social.

\footnotetext{
${ }^{18}$ Para su aplicación el derecho depende de la política y sin la perspectiva de esta imposición no existe ninguna estabilidad normativa convincente que sea atribuible a todos. La política, a su vez, utiliza el derecho para diversificar el acceso al poder concentrado políticamente (LUHMANN, 2002: 208; 2014).

${ }_{19}$ Pero la relación entre tiempo y estabilización de expectativas se da por medio contrafáctico, manteniendo una permanente contradicción con el entorno social, una vez que esas conexiones temporales normativas producen nuevas oportunidades de consenso y disenso, esto es, son situaciones en las cuales la propia decisión debe tomar partido en contra o favor de una determinada expectativa (LUHMANN, 2002:187).
}

Revista de Direito Brasileira | Florianópolis, SC | v. 24 | n. 9 | p.101-119 | Set./Dez. 2019 
Atrincherados por el ritual de las formas y de la corrupción, ${ }^{20}$ más bien se ha estabilizado una situación de complejidad desestructurada, en donde todas las posibilidades son iguales y arbitrarias y todos los poderes apelan a la razón del poder y no al sentido de poder de la razón.

Precisamente, el resultado de esta lógica operativa factual ha sido que en el país la experiencia política, jurídica y constitucional sea todo un 'éxito' en lo teórico, pero una rotunda desilusión en su operatividad (en su efectividad) y, sin embargo, esta 'desilusión' paradójicamente deviene la forma institucionalizada en la cual se ha coordinado y se orienta la confianza y orden social (ZAMORANO FARÍAS, 2017).

Al revisar las fuentes (Alcocer Palacios, 1980; Camp, 1981; Carpizo, 1997, 1998; Carrillo Prieto, 1986; Córdoba 1981; Cueva, 1957; De la Madrid, 1982; Echeverría, 1993; González Casanova, 1967; Meyer, 2000, 2005; Paré,1975; Salmerón Castro,1984; Stavenhagen,1981; Villoro, 1967), una primera constatación en la construcción del orden social en el México postrevolucionario, está marcada por la lógica del orden que estructura y naturaliza sus instituciones en torno a un sistema concéntrico dominante -a diferencia de los países de modernidades policéntricas-, en el cual el desarrollo autónomo de cada esfera se ha hecho dependiente del sistema central y los acoplamientos estructurales se han transformado prácticamente en procesos de desdiferenciación operativa (factual).

Esta forma de estructuración de un orden social concéntrico ha obstaculizado el despliegue de la especialización de otras funciones, dificultado así la función y legitimidad tanto del sistema jurídico cuanto, del sistema político, económico, educativo, científico, de la salud, del arte y hasta de la religión. Una estructuración, entre el régimen político-jurídico y las organizaciones de la sociedad, que funda las bases del corporativismo y cuyos actores centrales han sido desde siempre los sindicatos del sector público, las organizaciones oficialistas (indígenas, campesinas, obreras) y las diversas agencias del Estado controladas históricamente por el Partido Revolucionario Institucional (PRI). ${ }^{21}$

Al igual que en el caso de la Constitución de 1857, la articulación de la Constitución de 1917 no se correspondió con un desarrollo de las instituciones del Estado que permitieran la aplicación de la ley, ni con una sociedad civil moderna la cual, en la práctica, siguió careciendo de las condiciones de posibilidad para hacer efectivos los derechos más elementales. Más bien, la progresiva consolidación del régimen postrevolucionario significó la creación de leyes secundarias e instituciones estatales que convirtieron la aplicación de los derechos sociales en un mecanismo estatal de administración selectiva, clientelar y corporativa de esos mismos derechos.

Huelga decir que, por la naturaleza de su poder, la estructuración político clientelar corporativo requiere establecer siempre una fuerte relación emocional entre la 'patria', las 'instituciones' y los 'valores' de la voluntad e interpretaciones del líder, quedando los intereses colectivos en un segundo plano. Por lo tanto, uno de los problemas políticos más acuciantes, si queremos así definirlo, reside en un hecho que es inmediatamente perceptible; amparados sobre esta base institucional, se corrompen los códigos de diferenciación, cuanto menos por la imposibilidad de mantenerlos diferenciados de las innumerables influencias provenientes del entorno (LUHMANN, 2007). ${ }^{22}$

Por lo tanto, en la práctica jurídica y política, los derechos reconocidos en la Constitución

\footnotetext{
${ }^{20}$ Corrupción que no puede tipificarse como un problema cultural, sino que más bien deviene un problema institucional, toda vez que posibilita que las prácticas cotidianas estén por encima de las pautas normativas (estructuras que fomentan que la impunidad tenga preeminencia sobre el derecho), es decir, que la orden sea más importante que la norma. Operativamente, al imponer la orden personal por encima de la ley, el derecho se instrumentaliza, se hace discrecional y abre las puertas a todo tipo de impunidades y, por cierto, precisamente a la corrupción.

${ }^{21}$ Quienes quedaban fuera de estos encuadres, la mayoría de la población, simplemente no existían como sujetos políticos. Es decir, todos quienes no estaban insertos en las corporaciones o formasen parte de las redes clientelares.

${ }^{22}$ Que, sin embargo, desde siempre han pontificado y reclamado por la 'estricta aplicación de la ley', sin distinción alguna, mientras disponen de la ley a su antojo y según las posibilidades de sus relaciones de adscripción o, simplemente, están por encima la ley, porque 'ellos son la ley'.
} 
de 1917 fueron concedidos de manera gradual, arbitraria y clientelar a una pequeña parte de la población, que a cambio hubo de prometer fidelidad política al régimen e integrarse a los cuerpos y estructuras corporativas que éste diseñó, estabilizando la relación de súbdito con lo cual, operativamente, se anuló la creación y generación de la ciudadanía que presupone la actualización de un orden democrático (ZAMORANO FARÍAS, 2017).

Paralelamente, el poder ejecutivo se fundamentó en el principio fáctico del control del partido único por el presidente en turno, mientras el poder legislativo debía cumplir las ordenes del ejecutivo, quien en los hechos designaba a sus miembros en acuerdo con el partido único y los gobernadores. Así y de igual forma, el poder judicial debe desempeñar un rol fundamentalmente simbólico, al ser privado de los recursos y de la autonomía política que requería su función.

Históricamente, sobre la impronta del sistema presidencialista y del monopartidismo, el poder ejecutivo se impuso y estabilizó formas que, obliterando la función y tarea al resto de los poderes, opero metaconstitucionalmente. Es decir, aplicando poderes que se encuentran más allá del texto constitucional que, si bien, aún cuando no están establecidas de forma expresa en la Constitución, forman parte del contexto cultural y político del país: control del partido único, corporativismo y subordinación política de las organizaciones e instituciones sociales, principalmente del poder jurídico y del poder legislativo.

Estas lógicas de construcción del orden social postrevolucionario constituyeron un fértil caldo de cultivo para las prácticas de liderazgos clientelares (en cualquiera de sus versiones: caudillismo, amiguismo, cesarismo o bonapartismo), como patético resultado de la ambición desmedida de una 'inmensa minoría', signada hasta nuestros días por la incapacidad de articular y asumir operativamente el ethos que porta el pensamiento moderno.

En los años noventa, del pasado siglo, tras la apertura democrática (la así mal llamada transición democrática), junto con la creación y aparición de otros partidos políticos, así como de nuevas instituciones electorales, el prolongado carácter de las lógicas de construcción sociopolítica y jurídica no se modifico sustantivamente, lo que si se generó fue un demencial incremento del texto constitucional y una delirante elaboración de leyes y reglamentos casi sin precedentes en la historia (quizás para "contener la historia"). ${ }^{23}$

Así, en el año 2000 y tras la debacle del PRI, los gobiernos panistas que le sobrevinieron (2000 - 2012) hasta su retornó (2012), no hicieron otra cosa que profundizar y reestabilizar la structural drift de este tipo de orden social -violento, arbitrario y mafioso-. Amparados en el ordenamiento constitucional potenciaron y profundizaron el script político de la cultura mexicana, el cual se había sedimentado sobre la base de relaciones entre grupos sociales, mediadas por vínculos de poder, clasismo, corporativismo, clientelismo y, por cierto, por el miedo. (redes de inclusión local, vías informales de autoentendimiento en la representación y composición de los conflictos, relaciones socioeconómicas que influencian la política y el derecho -narcopolítica-, relaciones clientelares y corrupción).

Lo anterior puede leerse operativamente como la institucionalización de un orden social estratificado, un portento socio-cultural que ha penetrado y extiende su larga sombra en la sociedad mexicana, pero que, sin embargo, no constituye un fallo o una errada práctica aislada y puntual en el contexto de la sociedad funcionalmente diferenciada, sino más bien la forma estabilizada de cómo, en la práctica, el sistema funciona y se autorreproduce, y cuyas más lacerantes evidencias se

\footnotetext{
${ }^{23}$ Por ejemplo, en la carta constitucional se ha triplicado el número de palabras y prácticamente todos los acuerdos políticos entre los partidos se han llevado a sus páginas, convirtiéndola en un ordenamiento jurídico que reglamenta de manera extensa múltiples áreas de las políticas públicas, normas administrativas, y casi hasta con las normas de los concursos a las instituciones del Estado. Al año 2019 la Constitución de 1917, que originalmente tenia 21.000 palabras en 136 artículos, registra 699 enmiendas y 254 procesos de reforma, extendiéndose hasta las 65.500 palabras ("todo un éxito teórico").
} 
observan en la inaplicabilidad o disponibilidad del marco normativo que cautele a la obliterada, y también obsecuente, mayoría de los 'ciudadanos'. ${ }^{24}$

Si bien, desde la década de los años noventa del siglo pasado, se constata una relativa pluralización del sistema de partidos que amplia la rotación de élites, en su lógica factual no se observan cambios sustantivos, así como tampoco la administración institucional de las demandas sociales ni de las estructuras institucionales-electorales. Pensemos, por ejemplo, en la manipulación de las leyes electorales, en los fraudes de las elecciones presidenciales del año 2006 y del año 2012, avalados por el Instituto Nacional Electoral (INE), ex Instituto Federal Electoral (IFE). Un instituto de la corrupción, ${ }^{25}$ cuyos responsables en 1994 'perdieron' o les fueron 'robadas' las bases de datos del padrón electoral, cuando hoy es vox populi, vox Dei que simplemente las vendieron.

Instituto en donde los consejeros electorales inclusive pagan, del erario, desde la peluquería de sus mascotas hasta a sus empleados domésticos, mientas simulan por décadas su 'imparcialidad' y tanto Lorenzo Córdoba Villanelo, como sus antecesores, se pasean por los programas televisivos y Facultades universitarias para soltar sus peroratas sobre la de democracia, en contra de la corrupción y, como no, su irrestricto 'respeto' a las leyes.

Es ineludible, al respecto, recordar que, durante la etapa previa a la jornada electoral del año 2018, la ex primera dama Margarita Zavala, esposa del expresidente Felipe Calderón Hinojosa (2006 - 2012), fue la única postulante avalada por el INE para competir como aspirante a la presidencia, en el camino quedaron Ríos Pitter y Jaime Rodríguez. Solo que, del total de las firmas de apoyo para avalar la inscripción, 239 firmas presentadas por Zavala de Calderón eran inconsistentes, cuestión que incluso el INE reconoció, mas por alguna 'poderosa' razón no canceló su registro. El 'fundamento' del consejero presidente, Córdoba Villanelo fue que se trataba de "no violentarle el debido proceso".

De forma paralela, antes y durante el proceso electoral, se reactualizaron añejas prácticas políticas y electorales que se creían ya superadas: asesinatos selectivos (periodistas, mujeres y niños), uso electoral de programas sociales, compra, coacción e inducción del voto, acarreo y manipulación del electorado, propaganda del miedo y el revival del comunismo, en donde lo único que faltó mostrar en las televisoras fue la imagen de los tanques rusos invadiendo México. ${ }^{26}$

Con estas estructuras operando, hasta el último momento subsistió la duda de si el voto popular sería respectado y serviría -está vez- para elegir a los representantes políticos, pues ello ha 'dependido' hasta el día de hoy, de los entramados y contubernios de quienes tienen la

\footnotetext{
${ }^{24}$ A la sombra del formalismo legalista, de la politización del derecho y la juridificación de la política, de la fragilidad institucional, del autoritarismo clientelar y de la narcocracia, se han montado procesos electorales para impedir la representación proporcional, toda vez que la lucha electoral se hace cada vez más difícil por sus altos costos económicos. Lógicamente esto conduce al elitismo parlamentario y profundiza al liderazgo personalista que modula concepciones 'consensuales' de unos pocos. Ahora, si el sufragio representa un momento de horizontalidad de los ciudadanos, una igualación en el espacio público, una forma de ejercer la voluntad, de manifestar una creencia y un compromiso con programas y proyectos político-sociales, qué pasa cuando los sectores populares; campesinos, indígenas y obreros no tienen posibilidad de ser elegidos para representar sus intereses porque no poseen los recursos económicos que posibiliten solventar las onerosas campañas y marketing, y además cuando existe una serie de cortapisas -legales y no legales- que restringen institucionalmente la posibilidad de ejercer la ciudadanía.

${ }^{25}$. En su edición del día 06 de marzo de 2020, el periódico El universal publica la nota en donde señala que, en el INE, luego de la revisión del órgano interno de control, no se localizan 116 vehículos, por un valor que corresponde a 6.200.000 millones de pesos y tampoco 17.355 bienes muebles por un valor de 126.000 .000 de pesos. En la encuesta a nivel mundial Gallup 2020, de los países pertenecientes a la OCDE, de las instituciones evaluadas, el INE ocupa el primer lugar en la corrupción.

${ }^{26}$ Por último, no está demás recordar como un nutrido grupo vinculado a la narcocracia empezó a utilizar las estrategias y el discurso de miedo para sabotear el eventual triunfo de candidato a la presidencia, Andrés Manuel López Obrador, un 'presunto comunista'. Su objetivo fue hacer creer que, si López Obrador ganaba, el país se irá directo al despeñadero. Es exactamente lo mismo que hizo la derecha chilena contra Salvador Allende cuando en las elecciones de 1964 y 1970 difundió el miedo de que si ganaba la presidencia convertiría a Chile en una 'segunda Cuba' o en satélite de la entonces URSS.
}

Revista de Direito Brasileira | Florianópolis, SC | v. 24 | n. 9 | p.101-119 | Set./Dez. 2019 
responsabilidad de organizar y legitimar las elecciones (IFE/INE).

Del mismo modo, en está lógica clientelar y narcocrática, persiste la práctica de los nombramientos a dedo, ${ }^{27}$ cuyo ejemplo mas rutilante son los famosos diputados y senadores plurinominales (que no figuran en las boletas electorales), y quienes son determinados por quien gobierna el INE, y la compra de periodistas y comentócratas, delincuentes ignorantes capaces de opinar de lo divino y lo humano (chayateros les dicen en México) a cambio de prebendas y granjerías, merced a la impunidad y la corrupción sistemática. ${ }^{28}$ Esa vieja pero no menos eficaz práctica de la democracia mexicana, que se convierte en delito cuando así conviene al poder discrecional, y en donde la víctima es siempre culpable, si no tiene amicus curiae o, en la narcocracia.

Lo anterior evidencia y comprueba que en México nunca ha habido una democratización de los canales institucionales-electorales (así como tampoco en el resto de las organizaciones, piénsese en los sindicatos, las universidades o en el sistema educativo), y aun cuando es posible consignar y reconocer una relativa pluralización del sistema de partidos o de rotación de élites, no se han generado cambios sustantivos en las estructuras institucionales, así como en las condiciones de posibilidad para articular formas diferentes de organización jurídica, política y social.

Al contrario, esta normatividad estabilizada - dispersa y fragmentada-, se orienta compulsivamente a la proliferación de 'unidades', órganos y procuradurías judiciales que a lo único que contribuyen es a aumentar la inflación legalista (y los puestos a cargo del erario para la clientela), pero sin determinar claramente cuáles son los mecanismos de control y sobre qué de la norma. $^{29}$

Tal que las leyes se hacen $a d$ hoc, exculpando a priori y son aplicables, pero no para todos (la ley para mis enemigos), fomentado la impunidad y la cultura del incumplimiento, puesto que en ausencia de controles se promulga una nueva normativa, la cual nadie controla en su aplicación o posibilidades operativas de manera seria (examínense los juicios orales, mas allá de las jabonosas descripciones de la llamada 'sociología jurídica' mexicana). Sin embargo, se habla permanentemente de reordenar la Constitución y los mecanismos de control constitucional, de la necesidad de nuevas leyes o normativas, pero no queda claro qué es qué y quién hace qué (la federación, o el Estado). Todo esto sumado, además, al desorden en la forma de construir el estado de derecho, y principalmente a la carencia de estructuras sociales disponibles y operativas, así como también a la ausencia de capacidad técnica de los legisladores y de sus intelectuales orgánicos. ${ }^{30}$

\footnotetext{
${ }^{27}$ Que es reproducida por los gobernadores, jueces y magistrados, rectores, directores y 'dirigentes sociales', todos personal de confianza nombrado a dedo según el ritual procedimental que dicta la costumbre, y que imponen su voluntad en el resto de la administración, de las organizaciones políticas, laborales, científicas, académicas y electorales Un caso digno de mencionar es el del actual Presidente del -tenebroso- INE, Lorenzo Córdoba Villanelo quien, abusando de una 'curiosa' interpretación a modo de la ley, designó al secretario ejecutivo del Instituto por seis años más. Por ello y como dicen los colegas italianos: sembra che ha studiato al nord d'Italia ma si è laureato con la mafia siciliana...

${ }^{28}$ Testaferros del periodismo, anidados en los mass media para montar falsos positivos (Carlos Loret de Mola, Denise Dressser, Ciro Gómez Leyva, Brozo el payaso -literalmente-), quienes recibieron y reciben millones de pesos para general el caos y promover la desestabilización y el miedo. Al respecto, véase la investigación publicada por la periodista Nancy Flores en la Revista Contralínea (23 de febrero de 2020), en donde demuestra como ofertaban 'comentarios o cápsulas noticiosas', y el dineral que cobraban, señores como Joaquín López Dóriga, Federico Areola, Enrique Krauze, Oscar Mario Beteta. Callo de Hacha, Beatriz Pagés, Raymundo Riva Palacio, Ricardo Alemán, Adela Micha, Pablo Hiriart, Jorge Fernández Menéndez, Rafael Cardona; todos ellos 'respetables periodistas' y que constituyen solo una muestra de los beneficiados al amparo del poder y de la mafia corporativa.

${ }^{29}$ Extorsión, compra de votos, relleno de urnas, falsificación de actas, tergiversación de las cifras, manipulación del padrón electoral, excesos en los topes de campaña, falsas estadísticas del (Programa de Resultados Electorales Preliminares (PREP) y un sin fin de irregularidades, confirmando que el fraude electoral sigue siendo la práctica avalada, aceptada y defendida por malhadadas instituciones como el INE.

${ }^{30}$ No existe servicio de carrera sino personal de confianza que depende de quien lo elija. A la fecha, ni siquiera está claro cuántos desaparecidos hay en México, porque tampoco esta claro jurídicamente el concepto de desaparecido, así como tampoco el de feminicidio o de corrupción. Durante el primer encuentro nacional ante la situación de emergencia
}

Revista de Direito Brasileira | Florianópolis, SC | v. 24 | n. 9 | p.101-119 | Set./Dez. 2019 
Deviene evidente, entonces, que no se trata de generar más y más unidades, comités, fiscalías o procuradurías especiales -que son también más de lo mismo-, más aún cuando en la creación de la norma la autoridad competente y autorizada, no respeta o controla los principios formales y sustanciales establecidos en la Constitución, (KELSEN, 1992; LUHMANN, 2002; TEUBNER 2005 FERRAIOLI, 2011). Precisamente, el elemento clave de la diferencia entre las estructuras pre-jurídicas y jurídicas es la institucionalización del derecho para imponer la aceptación generalizada y despersonalizada de su contenido (LUHMANN, 2002), en caso contrario este debe ser considerado como inválido $\mathrm{y}$, por lo tanto, nulo, lo que equivale a decir que es jurídicamente inexistente.

Es evidente entonces que, cuando el voluntarismo personalista, y la corrupción política, pasan por encima de las instituciones terminan prácticamente por deformarlas, estabilizando como 'normal' la anormalidad institucional. Es decir, institucionalizando y estabilizando lo 'ilegal' como legal (ZAMORANO FARÍAS, 2017). ${ }^{31}$

\section{CONCLUSIONES}

Jeder nach seinen Fähigkeiten, jedem nach seinen Bedürfnissen

KARL MARX

(Kritik des Gothaer Programms, 1891)

Si una teoría sociológica aspira analizar los problemas de coordinación y construcción del orden social, no debe introducirlos como si éstos fuesen una ontología histórica o estuviesen axiomáticamente dados, más bien debe comenzar por asumir la realidad de una sociedad funcionalmente diferenciada y luego investigar cómo y por qué, en la construcción del orden social en la sociedad funcionalmente diferenciada, permanecen, se incrementan $\mathrm{o}$, inclusive, se estabilizan las lógicas estratificadas, pues y más allá de dogmas naturales, revolucionarios o axiológicos, éstas son las condiciones estructurales disponibles y los límites para observar cómo en su diferenciación funcional opera el orden social y las expectativas político-sociales y jurídicas.

Por tal razón, si bien he extendido la descripción de datos y ejemplos, el objetivo ha sido precisamente observar la forma en la cual, en México, operan el sistema del derecho y el sistema de la política, así como de las estructuras sociales disponibles sobre las que se despliegan y estructuran las prácticas y se estabilizan las expectativas. Es decir, analizar observar la construcción del orden social en la periferia de la sociedad moderna, e indicar las formas en que se estructura ese orden social generado y estabilizado, exactamente, sobre la base de las experiencias y de las expectativas que allí se producen.

(ciudad de México, 22 de octubre 2011), se informó sobre el geométrico avance de la penetración del narcotráfico en las instancias gubernamentales, es decir, la existencia de narcogobernadores y narcomunicipios.

${ }^{31}$ Durante el sexenio de Felipe Calderón Hinojosa (2006-2012), el ya frágil estado de derecho terminó definitivamente por metamorfosearse en estado de excepción. Sobre el fundamento de la guerra al narcotráfico (la cual nunca existió), en los hechos se efectivizo el derecho a la fuerza del Estado con la militarización de la vida social, el exterminio selectivo, la represión y consecuente generación del síndrome del miedo y de la violencia por fascinación (ZAMORANO FARÍAS y MAGNO LÓPEZ, 2020). Como confirman los datos duros, más de cien mil muertos, miles de desaparecidos, casi las tres cuartas partes del territorio nacional en disputa con el crimen organizado, fosas clandestinas por doquier, empresas extorsionadas, inseguridad y miedo generalizado. En el sexenio de Enrique Peña Nieto (2012 - 2018), de lo que se sabe, "más de 300 mil millones de pesos desviados por las distintas dependencias públicas, documentados por la Auditoría Superior de la Federación (ASF), cuyo destino se desconoce, podrían ser utilizados este año para la compra del voto, alertó el abogado Ricardo Peralta, candidato a Fiscal Anticorrupción, durante la presentación del libro Cleptocracia, el Nuevo Modelo de Corrupción, del periodista Jenaro Villamil" (REVISTA PROCESO, 2018, 25 de mayo). 
Al analizar las instituciones jurídicas y políticas mexicanas en su devenir evolutivo, se observa que el entorno social interno del sistema del derecho y del sistema de la política, aparecen como algo altamente complicado, mas no complejo, con la consecuencia de que ambos sistemas, en su operación se ven imposibilitados de remitirse a sí mismo, a su propia autonomía, a sus límites auto-establecidos, al código y a los filtros altamente selectivos que, al desbordarse o desdiferenciarse en su operación factual, terminan por suprimir su determinación estructural, llegando al extremo en donde ya no se puede hablar de clausura autopoiética e incluso tampoco de aprendizaje cognitivo respecto de las normas (LUHMANN, 2002: 138).

Evidentemente, la estabilización de la producción y reproducción histórica de estas determinantes de intervención, han decantado de forma inevitable en procesos de desdiferenciación operativa e incluso corrupción. Porque todo sistema, al estar expuesto frecuentemente a las intromisiones de otros sistemas (derecho-política /política-derecho), opera en estado de corrupción (LUHMANN, 2002: 137) y, si bien, por medio de sus operaciones reconoce que no puede resistir a la presión del entorno (política), se mantiene operando (simulando legalidad -en el caso del derecho-) sin renunciar a su especificación funcional.

Tal que la preeminencia de estructuras estratificadas hacen implausible, para el sistema del derecho y de la política, contrarrestar tanto la influencia extrajurídica, cuanto de las estructuras sociales y, por ende, las orientaciones de articulación social se hacen dependientes entonces de las relaciones de parentesco, de amistad y clientelismo, rutinizando así una cultura de derecho dependiente de la moral y del common sense e incluso, del sentido cotidiano de las palabras (LUHMANN, 2002: cap. VI).

Esa es forma en como se ha estabilizado el orden social en México, y también la dura realidad que hoy debe enfrentar el gobierno del actual presidente, con un orden social estructurado sobre la base de relaciones corporativas y en donde las condiciones sociales de posibilidad, que están a disposición, operan en la lógica de la corrupción, el clientelismo y la narcocracia, aún cuando quienes las controlan declaren y vociferen su permanente fe de demócratas, de defensores -y defensoras- de los derechos y de las instituciones, de la libertad de prensa, de estar en contra del crimen y la corrupción, e incluso, a tono con los tiempos, sean fervientes luchadores de los derechos de las mujeres, tal que incluso llegan hasta a transmutarse en feministas.

Un orden social que se despliega y construye en el presupuesto de la modernidad de la sociedad moderna, pero cuya preeminencia opera factualmente con arreos y esquemas premodernos, característicos de un orden social estratificado, el cual orienta las rutinas y las expectativas ciudadanas a todos los niveles, potenciando las relaciones y prácticas de corrupción e impunidad las cuales, más que debilitar, fortalecen las experiencias ciudadanas, incentivando la permanente oscilación entre la 'legalidad' de la ilegalidad que permea a profundis los intersticios orgánicos y estructurales de la sociedad mexicana (ZAMORANO FARÍAS, 2017).

Una realidad que, sin embargo, por dura que sea, puede ser más bella que los tonos nostálgicos de la ingenuidad...

México, marzo de 2020

\section{BIBLIOGRAFÍA}

ALCOCER PALACIOS, Mariano (Coord.) (1980). Federalismo y relaciones intergubernamentales, Porrúa-LIX Legislatura del Senado de la República, México.

CAMP, Roderic A. (1981). La formación de un gobernante. La socialización de los líderes políticos en el México post-revolucionario, Fondo de Cultura Económica, México.

CARPIZO, Jorge (1997). La Constitución de 1917, Porrúa, México. 
CARPIZO, Jorge (1998). El presidencialismo mexicano, Siglo XXI Editores, México.

CARRILLO PRIETO, Ignacio (1986). La ideología jurídica en la Constitución del Estado Mexicano 1812-1824, Universidad Nacional Autónoma de México, México.

CASTORIADIS, Cornelius (1990). Le monde morcelè, Èditions du Seuil, Paris, France

CASTORIADIS, Cornelius (2001). ¿"Qué democracia”?, Figuras de lo pensable, Fondo de Cultura Económica, México.

CASTORIADIS, Cornelius (2013). La institución imaginaria de la sociedad, Tusquets Editores, México

CÓRDOBA, Arnoldo (1981). La formación del poder político en México, Editorial ERA, México.

CORSI, Giancarlo (1998). "Redes de la exclusión”, Redes de inclusión. La construcción social de la autoridad, Miguel Ángel Porrúa-Universidad Nacional Autónoma de México, México.

CORSI, Giancarlo (2011). Ética y política, ponencia presentada en el XVI Congreso

Internacional de Filosofía de la AFM-Filosofía: "Razón y Violencia" (24-28 de octubre de 2011), Universidad Autónoma del Estado de México, Toluca.

CORSI, Giancarlo, Elena ESPOSITO y Claudio BARALDI (1996). Glosario sobre la teoría social de Niklas Luhmann, Anthropos-Universidad Iberoamericana-ITESO, México.

CUEVA, Mario de la (1957). El Constitucionalismo a medianos del siglo XIX. El

Constitucionalismo Mexicano (T. II), Universidad Nacional Autónoma de México, México.

DE LA MADRID HURTADO, Miguel (1982). Elementos de Derecho Constitucional, Editorial La Prensa, México.

DURKHEIM, Ëmile (2001). La división del trabajo social, Ediciones Akal, Madrid, España.

ECHEVERRÍA, Bolívar (1993). "Dos apuntes sobre lo barroco", Bolívar ECHEVERRÍA, Horst KURNITZKY (Coord.), Conversaciones sobre lo barroco, Universidad Nacional Autónoma de México, México.

ELIAS, Norbert (1994). El proceso de la civilización. Investigaciones sociogenéticas y psicogenéticas, Fondo de Cultura Económica, México.

FERRAJOLI, Luigi (2011). ¿Democracia sin Estado?, http://www.rebelion.org/noticia.php?id=121400 (31 de enero de 2011).

GONZÁLEZ CASANOVA, Pablo (1967). La democracia en México, Ediciones ERA, México.

HOBBES, Thomas (1994). Leviathan o la materia, forma y poder de una República, Eclesiástica y civil, Fondo de Cultura Económica, México. 
KANT, Inmanuel (1784). “Was ist Aufklärung?”, Berlinische Monatschrift, Deutschland.

KELSEN, Hans (1992). Esencia y valor de la democracia, Colofón, México.

KOSELLECK, Reinhart (1993). Futuro pasado, Ediciones Paidós, Barcelona, España.

KOSELLECK, Reinhart (2012). Historias de conceptos. Estudios sobre semántica y pragmática del lenguaje político y social, Editorial Trotta, Madrid, España, pp. 9-142.

LUHMANN, Niklas (1982). The Differentiation of Society, New York, Columbia University Press, USA.

LUHMANN, Niklas (1985). A Sociological Theory of Law, Routledge \& Kegan Paul, Londrés, Inglaterra.

LUHMANN, Niklas (1991). Sistemas Sociales: Lineamientos para una teoría general. Alianza Editorial-Universidad Iberoamericana, México.

LUHMANN, Niklas (1996). Confianza, Anthropos Editorial-Universidad Iberoamericana, Barcelona, España.

LUHMANN, Niklas (1998). "Causalità nel Sud", CORSI, Giancarlo e Raffaele DE GIORGI. Ridescrivere la questione meridionale, Pensa Editore, Lecce, Italia.

LUHMANN, Niklas (1998b). Complejidad y modernidad. De la Unidad a la diferencia, Editorial Trotta, España.

LUHMANN, Niklas (2002). El derecho de la sociedad, Universidad Iberoamericana, México.

Luhmann, Niklas (2004). La política como sistema, Fondo de Cultura Económica, México.

LUHMANN, Niklas (2004b). Do sistema social à sociología jurídica, Lumen/Juris Editora, Rio de Janeiro, Brasil.

LUHMANN, Niklas (2005). El derecho de la sociedad, Herder Editores, México.

LUHMANN, Niklas (2006). Sociología del riesgo, Universidad Iberoamericana, México.

LUHMANN, Niklas (2007). La sociedad de la sociedad, Herder Editores-Universidad Iberoamericana, México.

LUHMANN, Niklas (2010). I diritti fondamentali come istituzione, Dedalo, Bari, Italia.

LUHMANN, Niklas (2010b). Organización y decisión, Herder Editores-Universidad, México.

LUHMANN, Niklas (2010c). Potere e complissitá sociale, ilSaggiatore/Tascabili, Milano Italia.

LUHMANN, Niklas (2010d). Cómo es posible el orden social, Herder Editores-Universidad, 
México.

LUHMANN, Niklas (2015). Comunicaciones y cuerpo en la teoría de los sistemas sociales, Universidad Nacional Autónoma de México-La biblioteca.

MACHIAVELLI, Nicolò (1980), Il Principe, Valdonega, Verona, Italia.

MEYER, Lorenzo (2000). “Los caciques: Ayer, hoy ¿y mañana?”, Revista Letras Libres (diciembre), México.

MEYER, Lorenzo (2005). El Estado en busca del ciudadano. Un ensayo sobre el proceso político mexicano contemporáneo, Océano, México.

PARÉ, Luisa (1975). Caciquismo y poder político en el México rural, CIIS-UNAM, Siglo XXI Editores, México.

PARSONS, Talcott (1987). El sistema de las sociedades modernas, Editorial Trillas, México.

SALMERÓN CASTRO, Fernando (1984). “Caciques. Una revisión teórica sobre el control político local”, Revista Mexicana de Ciencias Políticas y Sociales, XXX (117-118), Universidad Nacional Autónoma de México, México, pp. 107-141.

STAVENHAGEN, Rodolfo (1981). "Siete tesis equivocadas sobre América Latina", Sociología y subdesarrollo, Nuestro Tiempo, México.

TEUBNER, Gunther (2005). Direito, sistema e policontexturalidade, Editora UNIMEP, São Paulo, Brasil.

TEUBNER, Gunther (s/f). O direito como sistema autopoiético, Edição da Fundação Calouste Gulbenkian, Lisboa, Portugal (Tradução do original alemão Recht als Autopoietisches Systems, 1989).

VILLORO, Luis (1967). El proceso ideológico de la Revolución de Independencia, Universidad Nacional Autónoma de México, México.

WEBER, Max (1980). Economía y Sociedad, Fondo de Cultura Económica, México 1980.

WEBER, Max (1989). La sociología del derecho, Universidad Nacional Autónoma de México, México.

ZAGREBELSKY, Gustavo, Pier Paolo PORTINARO, Jörg LUTHER (Coord.) (1996). Il futuro della costituzione, Einaudi, Torino, Italia.

ZAMORANO FARÍAS, Raúl (2017). Observando el orden social en México: el sistema de la política y el sistema derecho, Juan Pablos Editor, México.

ZAMORANO FARÍAS, Raúl y Alejandro MAGNO LÓPEZ (2020). "El imaginario instituido de la violencia por fascinación en México", CAMARENA, Margarita (Coord.). Ciudad de México: Miradas, Experiencias, Posibilidades, IISUNAM, México (en dictamen): 


\section{Hemerografía}

CONTRALINEA.COM.MX (2020). 23 de febrero, México, https://www.contralinea.com.mx/archivo-revista/2020/02/23/presidencia-entrega-documentos-derelacion-comercial-del-gobierno-de-pena-con-periodistas/

PERIÓDICO EL UNIVERSAL (2020). 03 de marzo, México https://www.eluniversal.com.mx/nacion/se-le-pierden-al-ine-116-vehiculos-y-17-mil-bienes

REVISTA PROCESO (2018). 23 de mayo, México https://www.proceso.com.mx/535840/alertan-posible-uso-de-mas-de-300-mil-mdp-para-elfraude-electoral-jenaro-villamil-presenta-su-libro-cleptocracia 